\title{
Cuerpos, devenires y otras existencias
}

\section{Bodies, transformations and other existences \\ Corpos, transformações e outras existências}

\section{Claudia Piedrahita Echandía}

Universidad Distrital Francisco José de Caldas

E-mail: claluz7@gmil.com

Recibido: 11: 07: 2018

Aceptado: 26:09:2018

\section{Resumen}

El objetivo de este artículo es presentar una perspectiva teórica y crítica sobre cuerpos insurgentes que rompen con las corporalidades organizadas, el yo, la identidad y las capturas de la subjetivación para experimentar en un devenir animal/monstruo. Esta perspectiva sobre cuerpos monstruosos la estaremos abordando a partir de conceptos que surgen de la filosofía de la diferencia de Deleuze y Guattari, enfatizando en el devenir, el devenir animal/monstruo y el Cuerpo sin Órganos. Planteamos la emergencia de cuerpos que transitan en un plano de inmanencia y que generan resistencias a las capturas del plano de organización, pero que también expresan límites a la experimentación, entendida ésta como práctica prudente y afirmativa. El artículo recoge la perspectiva teórica de dos tesis doctorales sobre subjetivaciones, cuerpos y diferencias inscritas en la línea de investigación en Subjetividades y Diferencias del Doctorado en Estudios Sociales de la Universidad Distrital Francisco José de Caldas de Bogotá.

Palabras Claves: Cuerpos, desubjetivación, devenir animal, devenir monstruo 


\section{Abstract}

The objective of this article is to present a theoretical and critical perspective on insurgent bodies that break with organized corporeality, the self, the identity and the captures of subjectivation to experience in an animal / monster becoming. This perspective on monstrous bodies will be revised based on concepts of Deleuze and Guattari's philosophy of difference, mainly the becoming, the animal / monster becoming and the Body without Organs. It will consider the appearance of bodies that travel in a plane of immanence and that generate resistance to the captures of the plane of organization, as well as the expression of limits to experimentation, understood as prudent and affirmative practice. The article includes the theoretical perspective of two doctoral theses on subjectifications, bodies and differences inscribed in the line of research in Subjectivities and Differences of the Doctorate in Social Studies of the Universidad Distrtital Francisco José de Caldas of Bogotá.

Key Words: Bodies, desubjectivation, becoming animal, becoming monster

\section{Resumo}

O objetivo deste artigo é apresentar uma perspectiva teórica e crítica sobre corpos insurgentes que rompam com a corporeidade organizada, o self, a identidade e as capturas da subjetivação para vivenciar um devir animal / monstro. Essa perspectiva sobre corpos monstruosos será revisada com base nos conceitos da filosofia da diferença de Deleuze e Guattari, principalmente o devir, o devir animal / monstro e o Corpo sem Órgãos. Considerará a aparição de corpos que viajam em um plano de imanência e que geram resistência às capturas do plano de organização, bem como a expressão de limites à experimentação, entendida como prática prudente e afirmativa. O artigo contempla a perspectiva teórica de duas teses de doutorado sobre subjetivações, corpos e diferenças inscritas na linha de pesquisa em Subjetividades e Diferenças do Doutorado em Estudos Sociais da Universidade do Distrito Francisco José de Caldas de Bogotá.
Palavras chave: Corpos, dessubjetivação, tornando-se animal, tornando-se monstro

\section{Cuerpos, devenires y otras existencias}

El organismo no es en modo alguno el cuerpo (...) sino un estrato en el $\mathrm{CsO}$, es decir, un fenómeno de acumulación, de coagulación, de sedimentación que le impone formas, funciones, uniones, organizaciones dominantes y jerarquizadas, transcendencias organizadas para extraer de él un trabajo útil.

(Deleuze, 1994: 164) Mil Mesetas

\section{Introducción}

Introducirnos en el devenir monstruo es en primera instancia entender la vida de una manera "no orgánica" (Deleuze y Guattari, 1994) y "no personal" (Deleuze y Parnet, 1980), esto es, una vida que transcurre en su máximo nivel de desterritorialización, en la potencia de la creación y en una apuesta por la desubjetivación. Coherente con esto, la propuesta de este artículo está referida a la configuración de cuerpos conectados a unas intensidades y afectos que sobrepasan todas las formas de organización y además cuerpos con posibilidades mutantes que le apuestan a la despersonalización y que transitan en el devenir monstruo.

En el centro de esta propuesta sobre devenir monstruo está el concepto de experimentación desarrollado por Deleuze en Mil Mesetas; para este autor, nadie sabe de antemano lo que le conviene. "Nadie, ni siquiera Dios, puede decir de antemano si dos bordes se hilaran o constituirán 
una fibra, si tal multiplicidad pasará o no a tal otra, o si tales elementos heterogéneos entrarán ya en simbiosis, constituirán una multiplicidad consistente (...) Nadie puede decir por donde pasará la línea de fuga" Deleuze y Guattari 1994:255). No es posible saber previamente que le conviene a un cuerpo, o sea, que encuentros son lo que más convienen y cuáles traerán afectos alegres. Igualmente, tampoco es posible saber que puede un cuerpo o hasta donde puede mutar sin experimentar con la despersonalización.

Devenir monstruo involucra entonces experimentación y desestratificación; acercando este concepto a la propuesta deleuziana de hacerse un Cuerpo sin Órganos-CsO y desubjetivarse, implica crear un cuerpo que logra liberarse de las tres ataduras de la estratificación: la organización, la subjetivación y la significación. El devenir que se libera en la desestratificación y la experimentación se configura entonces a través de tres destinos a) inorgánico: se deviene imperceptible en tanto se disuelve la organización y se crea un $\mathrm{CsO}$. Desaparece la forma organizada asignada y se deviene gris sobre gris b) asignificante: se deviene indiscernible, o lo que no puede ser nombrado, lo que no está significado c) asubjetivo: se deviene impersonal; se difumina la identidad, el ego y el yo y aparece la inmanencia de una vida.

Este artículo estará más centrado en lo inorgánico y lo asubjetivo, como dos destinos del devenir. En esta dirección, definiciones que se relacionan con la desorganización, la desubjetivación y la disolución de ego serán el punto de entrada a la comprensión del devenir monstruo; además, la experimentación como operación que disuelve la captura de los cuerpos en un plano de organización, tendrá también un lugar central en esta discusión.

En esta perspectiva tanto lo inorgánico, representado en el CsO, como lo asubjetivo que emerge como despersonalización, nombran experiencias de margen o pasaje a una vida que transita en las conexiones extrañas, los contagios, las mutaciones y conversiones. Igualmente, este devenir monstruo involucra la prudencia enunciadas por Deleuze y Guattari (1994), ya que una experimentación es también una línea que se juega entre la vida y la muerte. Lo deseable para este autor es mantener un mínimo de estratificación que permitan el tránsito entre la organización y la composición, pero que al mismo tiempo preserve la vida y el deseo.

Finalmente, lo que va surgiendo como hipótesis, es que el devenir monstruo implica un trabajo sobre sí mismo, que rompa las capturas molares y las ataduras del ego y que permita mutar hacia una vida que fluye en lo imperceptible. Es una muerte aparente, o un paso a otra forma de vida. Sobre este punto volveré en las conclusiones.

El interrogante central en esta discusión no está en el orden de lo identitario y la esencial sino en las potencias y las diferencias. La pregunta central no es ¿Qué es un cuerpo? ya que este interrogante nos lleva a una identidad estática y a una respuesta estética y política predeterminada; la pregunta es ¿Qué puede un cuerpo? ¿Cómo experimenta? o ¿Cómo hacerse un cuerpo des-organizado o $\mathrm{CsO}$ ? Y además, ¿Cómo desde el cuerpo es posible constituir un dispositivo estético- político que desdibuje identidades consolidadas para transitar en un devenir inhumano, animal, monstruo e imperceptible?

\section{La desestratificación del organismo}

La desestratificación del organismo da paso a una idea de cuerpo abierto a la multiplicidad, la inmanencia y a una vida que se juega entre lo orgánico y lo no orgánico que no implica algo sobrenatural, etéreo o un escape del cuerpo material; por el contrario, des-estratificarse y des-subjetivarse implica una experiencia de salir hacia el cuerpo, pero hacia un cuerpo que puede contagiar, afectar y ser afectado y que está siempre en capacidad de experimentar encuentros y relaciones con otros cuerpos. Ahora, en esta visión ontológica se afirma que lo que impulsa estas conexiones es el deseo afirmativo y no el deseo como carencia, planteado por el psicoanálisis freudiano. Es un deseo que no está interiorizado y que 
se constituye precisamente en el encuentro con otras corporalidades con las cuales se comparte, no segmentariedades, sino intensidades y afectos que funcionan como máquinas deseantes que eventualmente producen líneas de fuga que alcanzan el nivel máximo de des-territorialización deviniendo imperceptible. Esto implica un procesos de desubjetivación, o "haber deshecho su propio yo para estar por fin solo, y encontrar el verdadero doble en el otro extremo de la línea (...) pero este devenir es sólo precisamente para aquel que sabe no ser nadie, ya no ser nadie. Se ha pintado gris sobre gris" (Deleuze y Guattari, 1994: 202)

Los afectos tienen un lugar central en este proceso de desorganización que finalmente nos lleva a transitar por los cuerpos monstruosos y al devenir monstruo. Los afectos dan cuenta de lo que puede un cuerpo, esto es, de la capacidad para establecer conexiones, dejarse afectar y establecer resistencia frente a formaciones molares que restringen el potencial de un cuerpo para expresar su intensidad, en tanto que capturan el deseo y separan el cuerpo de lo que puede hacer. Esta sería la diferencia entre un cuerpo organizado y un cuerpo que experimenta desde un deseo libre que no tiene objeto, ni compromiso. (Braidotti, 2005: 134)

En esta propuesta sobre cuerpos des-organizados que proviene del nomadismo filosófico, ya no existe una lucha entre cuerpo y mente, sino entre diferentes modos del Cuerpo (Lee y Fisher 2009: 80) algunos de los cuales se anclan en la estratificación y otros luchan contra ella en tanto que se abren a la experimentación y en algunos casos avanzan hacia los límites, o al máximo de desterritorialización o CsO. La propuesta ontológica y política siempre estará orientada a una experimentación que provoque la desarticulación del organismo y la des-subjetivación, pero a través de una estética de la prudencia que enfrente los peligros y maneje las dosis y las sobredosis que pueden llevar a la autodestrucción y la muerte. (Deleuze y Guattari, 1994: 164) En la experimentación con el $\mathrm{CsO}$ siempre acecha la posibilidad de una línea inversa de muerte. A esto se refieren Deleuze y Guattari cuando nos presenta el escenario sombrío de los cuerpos hipocondríacos, paranoicos, esquizofrénicos, drogadictos, masoquistas que no supieron dosificar la experimentación y sus secuencias y que fracasan en la des-organización del cuerpo.

Así pues, en la comprensión del devenir monstruo, el desdibujamiento del plan de organización representado en el Cuerpo sin Órganos, adopta un lugar central, dado que logra hacer visible lo intensivo o la diferencia diferenciante $^{2}$ en las existencias materiales de los individuos. El CsO se entiende como el punto de entrada al deseo puro y a los tránsitos por la inmanencia o la posibilidad de escapar a lo organizado. Este concep-

2 Deleuze, (2009) en su texto sobre Diferencia y Repetición, aborda este problema a partir de los conceptos de diferencia en sí misma y repetición para sí misma, que no son lo mismo que diferencia respecto de algo que se encuentra representado y tampoco repetición como estereotipo. Se plantea un concepto de diferencia diferenciante que transita por fuera de un original predeterminado y que constituye la virtualidad del simulacro. Lo virtual no es análogo a lo posible ya que no tiene semejanza en el sistema de representaciones; es siempre diferencia, diferenciación, divergencia. Igualmente el concepto de repetición para sí misma, no incluye la repetición en bruto, sino la vivencia de todas las conexiones experimentadas en un pasado puro y que al ser vividas en el presente adquieren un nivel de máxima concentración que le confiere la mayor potencia a la acción. Este concepto de pasado puro lo retoma Deleuze de Bergson. No está limitado a lo vivido sino que es un movimiento incesante entre pasado y presente que se enriquece en cada momento. Todo el pasado emerge mezclado con el presente en un instante, constituyendo de esta manera la diferencia en sí. Lo que retorna son todas las fuerzas, las voces, las experimentaciones que rompen con lo representado para dar lugar a lo virtual. La diferencia diferenciante se recrea en el simulacro que desdibuja el modelo y la copia, constituyéndose como elemento estético y también de experimentación política y creación que transita entre el desplazamiento, la condensación y la dramatización (Mengue, 2008). El simulacro muestran la posibilidad de avanzar en una forma de existencia despersonalizada y desubjetivada-diferencia/diferenciante- sin modelo ni fundamentos o puro devenir y experimentación que desequilibra el orden de la identidad y la semejanza y remite a una apuesta por un plano de composición donde nos inventamos de manera permanente. Des-sujetarnos de la semejanza es también la posibilidad de abrirno a la experimentación o a lo que puede ser y que no está atrapado en el presente. En la diferencia/diferenciante se transita en una resistencia configurada en un tiempo-devenir que le apuesta a las líneas de fuga y a un espacio creado, o sea, espacios lisos, no estratificados, no pre-existentes sino configurados en relación a ciertas prácticas de territorialización y maneras de existir que responden a dos interrogantes: ¿Cómo se ocupa un espacio? ¿Qué ocupa un espacio? ¿Cómo van mutando las existencias en el acontecimiento y las líneas de fuga? (Deleuze y Guattari, 1994). 
to filosófico está referido a prácticas políticas y experimentaciones que configuran un devenir animal/monstruo/imperceptible que se juega en la multiplicidad, el contagio, el exceso, el riesgo y el desdibujamiento de las fronteras. $\mathrm{El} \mathrm{CsO}$ es devenir permanente y mutaciones que no prevalecen en el tiempo y que no hacen relación a un individuo en particular, sino a una constelación de conexiones o bloques de devenires, con posibilidades de contagio o de afectar y ser afectados.

\section{Devenir animal o bloques de devenir}

Deleuze en su diálogo con Negri, recogido en el texto Conversaciones (1999), establece la importancia de hacer una diferencia entre historia y devenir, ligando más éste último al acontecimiento, o a aquello que irrumpe para producir mutaciones. La historia muestra el estado de las cosas pero no los componentes, las experimentaciones y los contagios que dan lugar a bloques de devenir y a la creación. El devenir, al mostrar todos estos elementos, se aparta de la historia, puesto que precisamente para devenir y crear algo nuevo, debe hacerse una ruptura con la historia y configurar un devenir animal, devenir monstruo, o como lo plantea Deleuze, un devenir revolucionario de la gente, que precisamente da lugar a otra forma de existir, otra gente, otra manera de pensar un mejor mundo para todos. El devenir siempre está impulsado por afectos y deseos colectivos, o sea, por conexiones externas que no están supeditadas a la historia y el control racional.

Ahora, concretamente el devenir animal, hace relación al desdibujamiento de las fronteras entre lo humano y lo no-humano y al énfasis en una contaminación que interconecta lo animal, la naturaleza, lo humano, restándole centralidad y trascendencia al hombre o al ideal estético y moral articulado a lo racional, blanco, europeo, hetero y masculino. El devenir animal se interconecta con un territorio que no se posee o se domina; éste se cruza en manada configurando un cuerpo nómada en el que se difuminan las especies para confluir en bloques de devenir que no producen otra cosa que sí mismos. O sea, en los bloques de devenir, o el devenir animal, los términos desaparecen y aparece el cuerpo nómada. Y también, en esta misma dirección y más en referencia a procesos políticos, se constituyen "máquinas de guerra", que no implican alguna forma de violencia sino una cierta manera de ocupar el espacio-tiempo o de inventar nuevos espacios- tiempo (Deleuze, 1999) En este componente político del devenir animal cobra mucho sentido la ficción y la experimentación, ya que desde allí se logran desmarcar los modelos estéticos que segmentarizan las existencias contemporáneas. Ahora, lo que es propio del devenir animal es que no hay modelo y siempre hay contagio, y de ahí, precisamente, viene su potencia y su resistencia creadora: en el contagio y la fabulación.

El devenir animal opera entonces por contagio y no por filiación puesto que ésta da lugar a las copias y los duplicados. Por el contrario se avanza hacia la creación, a través de una implosión que pone en juego reinos completamente diferentes, sin ninguna filiación posible y que dan lugar a lo nuevo. Implosionar no es regresar, es simbiosis, contagio o lo que es propio del devenir animal que opera como bloques y como multiplicidad representada en la manada y el enjambre, donde lo específico y lo particular queda totalmente diluido. Sin embargo, a partir de la multiplicidad cualitativa a la que apelan Deleuze y Guttari (1994) es posible hacer una diferencia entre masas y bandas, o entre unidades molares y multiplicidades moleculares que puede darle mayor comprensión al devenir animal. En la primera predomina la similitud entre los miembros, las jerarquías y comparaciones y la organización y estabilidad del territorio. En la segunda, o en la manada, hay dispersión, transformaciones, jerarquías variables y desterritorialización. La relación del individuo con la manada o banda, siempre está en el límite, mientras que en la masa hay una concentración lejos de las fronteras. (Eliade, 1998)

Recurrir a lo animal para dar cuenta de los bloques de devenir que dan lugar a lo nuevo, no tiene un sentido metafórico; se busca enfatizar en las potencias transformadoras y la memoria encarnada e inscrita en los cuer- 
pos de los animales, para, a través de estos aspectos, comprender corporalidades que expresan la zoe o una vida vivida a su máximo nivel de expansión que supera los obstáculos del ego, el significante y la carencia. En el proceso de devenir animal hay una transformación cualitativa que permite ampliar las conexiones y constituir agenciamientos colectivos.

El devenir animal, expresa vidas transhumanas, experiencias en manada, no unitarias e interconectadas, que transcurren articuladas a un territorio que siempre se protege. El devenir animal, es entonces "mutaciones, afectos, y relaciones incesantes (...) regidas por principios de afinidad, (...) o sea de entrar en relación con otra entidad para producir encuentros alegres. Son una expresión de la propia potentia y aumentan la capacidad del sujeto para entrar en sucesivas relaciones, para crecer y expandirse". (Braidotti, 2005:169).

En general el devenir animal, es una manera de existencia de vivir un cuerpo que rompe con el imperio de la conciencia y la racionalidad y que se alía con la vida, con zoe, entendida ésta como fuerza afectiva impersonal y desubjetivada que se acerca a lo posthumano, al estallar las fronteras de un cuerpo demasiado humano generando un continuo hacia lo indómito y lo animal que escapa a la captura de lo organizado. Expresa también la codependencia del cuerpo con un territorio del cual se nutre y con el que mantiene una relación de cuidado. Por todo lo anterior, constituye una verdadera experimentación que no es negativa y restrictiva y que transita a través de intensidades, flujos o afectos complejos que están más allá del bien y del mal, que nos habitan y dan cuenta de los sujetos en los que nos estamos convirtiendo.

\section{Devenir monstruo: más allá de lo estático}

Antes de entrar en la discusión sobre el devenir monstruo, es importante hacer la distinción que hace Deleuze entre monstruo extático y estático. El monstruo estático no disuelve las formas pre-existentes. Las identidades permanecen representadas en formas que no dejan surgir el fondo.
Es más cercano a un calco o un pastiche que a un devenir monstruo. Por su parte el monstruo extático existe en lo inmanente, disuelve las formas anteriores, avanzando hacia lo nosntruoso/imperceptible. Son cuerpos despersonalizados que avanzan por sí mismos, en la fuerza de los afectos que van desdibujando sus formas anteriores, logrando devenir imperceptibles. El monstruo extático es más cercano a Drácula o al devenir vampiro que refleja la diferencia con sí mismo que se abre a múltiples puertas sin ningún orden lógico y que no cesa de metamorfosearse. Es el vampiro que deviene enjambre de moscas, neblina, lobo, con una estabilidad temporal que se desdibuja en nuevas líneas de fuga. Hay un paso del hombre, al animal, al vegetal, a las moléculas, que no es evolución u orden lógico sino "compatibilidad alógica" azar, puro devenir. (Deleuze y Guattari, 1994)

El devenir monstruo se comprende en relación con salir de un cuerpo organizado e ir hacia un cuerpo que se reinventa, o a una experimentación que consume el organismo original y que nos lanza fuera de nosotros mismos. Aquí se encuentra una clave que hace la diferencia entre el devenir animal y el devenir monstruo/imperceptible, en tanto que se involucran metamorfosis que se suceden en consonancia con ocasiones exteriores y que se expresan como automultiplicación, autodescomposición y autoingestión. En el devenir monstruo hay una muerte simulada que da lugar a alumbramientos y multiplicaciones que despliegan otra vida que no es enteramente humana y tampoco un organismo. "Es máquina abstracta que captura, transforma, y produce interconexiones" (Braidotti, 2005: 278) Entonces, en la metamorfosis que no es imitación o simple trasformación de formas externas, se crea un fluir de la existencia que representa una conversión que no atenta contra la vida. El devenir monstruo, pasa por el devenir animal y por el contagio con lo Anomal (Deleuze y Guattari, 1994) o figuración que define los márgenes de la manada. El Anomal, como lo plantea Deleuze, es al mismo tiempo fenómeno de frontera, fuerza excepcional, individuo extraño, diablo, vampiro, con potencia para ir al Afuera. 
El cuerpo organizado que deviene animal, manada, se contagia de lo anomal que está en la frontera de la manada y devine monstruo extático a través de conexiones extrañas o ceremonias de brujos (Deleuze y Guattari, 1994) que lo llevan a una zona de indiferencia y de imperceptibilidad. Ahora, lo monstruoso siempre va a evocar fascinación, odio y rechazo, en tanto que representa poderes extraños, o "las ansiedades negativas o reactivas de lo mayoritario" (Braidotti, 2005: 245) representadas en lo que escapa a lo antropocéntrico y moralizante o en metamorfosis no controladas que hacen emerger precisamente lo que Deleuze denomina como diferencia-diferenciante.

Deleuze en Nietzsche y la Filosofía (1971) plantea que el devenir es diferencia con uno mismo, y en Diferencia y Repetición (2009), afirma que la diferencia es precisamente el monstruo, así que lo que se logra en la filosofía del devenir es la reconfiguración del valor de la diferencia y la conceptualización del devenir monstruo como capacidad para metamorfosearnos, resistir y sobrevivir en este mundo contemporáneo. Y también para desdibujar fronteras entre lo humano y lo no humano; lo blanco y lo negro; lo masculino y lo femenino; el norte y el sur. El devenir monstruo es la señal de algo que ya está ocurriendo y que resquebraja los cuerpos organizados, blanqueados y los devenires mayoritarios. Es, como lo plantea Haraway, la promesa de los monstruos que da cuenta de una ontología y una política que desmarca posiciones de sujeto esenciales y fijas, en tanto que visibiliza sujetos sociales emergentes, denominados por esta autora como los cyborg o los «otros inapropiados/ inapropiables" que ya habitan este mundo y se configuran como "una implosión de lo técnico, lo textual, lo orgánico, lo mítico y lo político en los pozos gravitacionales de la ciencia en acción”. (Harawey, 1999:126)

\section{Conclusiones}

Ahora, volviendo a la hipótesis central en este artículo que establece la importancia del trabajo sobre sí mismo en el devenir monstruo, es ineludible, para finalizar, enfatizar en el devenir imperceptible y la des-subje- tivación, asociados a procesos de tensamiento sensorial y perceptual que incrementan la libertad y la potencia en una vida cada vez más intensa. Con esta hipótesis volvemos a la afirmación de Deleuze y Guattari de ir más allá de lo orgánico y lo subjetivo, o sea, a desestratificar el cuerpo y enfrentar el CsO. Estas prácticas están más del lado de la ciencia ficción, el chamanismo y la estética que de la ciencia o la filosofía en tanto que configuran una forma de recuperar la experiencia de abrirse al cosmos a través de un contagio con lo Anomal o el máximo de desterritorialización. Este encuentro, que es ejemplificado por Deleuze y Guattari a través del Outsider de Lovecraft, es "la Cosa que llega y desborda por el borde, lineal y sin embargo múltiple, rebosante, efervescente, tumultuosa, espumeante, que se extiende como una enfermedad infecciosa, a ese horror sin nombre" (Deleuze, citado por Lee y Fisher, 2009: 92).

En referencia a esta hipótesis, devenir monstruo es experimentar intencionalmente hacia una corporalidad expandida, ampliada (Lee y Fisher, 2005) que disuelve los límites del yo sin caer en la psicosis, o en una línea de fuga inversa. Es tener claro que en un mundo en devenir la forma apropiada de vivir es la experimentación y la propagación o el contagio. A esto hacen referencia Deleuze y Guattari (1994) en su discusión sobre los brujos en su "meseta" sobre el devenir. Para estos autores, el brujo es quien experimenta y lo hace consigo mismo, desde su propia vida, constituyendo verdaderas metamorfosis que transitan en lo pre-individual y lo contranatura que instaura el devenir monstruo. Este devenir incluye en la reterritorialización no sólo procesos articulados al devenir animal, como la propagación y la proliferación, sino una propuesta existencial y espiritual que implica una conversión, o una práctica de desubjetivación o desestratificación con claros efectos políticos y enmarcado esto en una práctica prudente de experimentación.

En la conversión el cuerpo organizado ha de ser deshecho, de manera prudente, o sea, arriesgando precisamente la vida, para dar paso a un devenir monstruo. Ahora, estos procesos de desubjetivación, se presentan de manera más comprensible a través del arte. Por esta razón voy 
a recurrir a la escritora Clarice Lispector, quien en su texto "La pasión según GH" (2013) hace referencia no sólo a un contagio, sino a la incorporación de lo abyecto y repugnante en el cuerpo de la protagonista de su novela, representada esta figura en una cucaracha. A partir de este encuentro intensivo, de este devenir insecto, se produce una despersonalización y “desheroización” en GH (Lispector, 2013) que se traduce en la supresión gradual de todos los estratos que configuran su subjetividad en un plano de organización, para confluir en la inmanencia y conexión cósmica.

Sabía que tenía que comerme la masa de la cucaracha, pero comérmela toda, y también comerme mi propio miedo. Comer la masa de la cucaracha es el antipecado, pecado asesino de mi misma. El antipecado. Pero a qué precio. Al precio de pasar a través de una sensación de muerte. Me levanté y avancé un paso, con la determinación no de una suicida, sino de una asesina de mi misma. (Lispector, 2013: 142).

Esta narración refleja la muerte del organismo, de lo subjetivo que da paso al devenir monstruo imperceptible. Se recurre a una figura de muerte para vivir de otra manera.

(...) algo había ocurrido y no quería pensar, pero sabía. Tenía miedo de sentir en la boca lo que estaba sintiendo. (...) y como quien regresa de un viaje, volví a sentarme tranquila en la cama. Yo que había pensado que la mayor prueba de transmutación de mí en mí misma sería ponerme en la boca la masa blanca de la cucaracha y así aproximarme a lo divino que es para mí lo real. (Lispector, 2013: 143).

El relato de GH muestra la manera como se deviene insecto/monstruo/ imperceptible o la desaparición de la persona, del ego civilizado que se funde con todo lo vivo (Braidotti, 2005). La vida que surge de la conexión con el evento intensivo se entiende entonces como una fuerza impersonal, sin código ni representación, que persiste y pasa a través de lo humano para interconectarse con un exterior que es cósmico, o sea, infinito
Esta fuerza de la vida que describe Lispector y que hace corte con la linealidad de la vida anterior de GH, excede cualquier concepto clásico de subjetividad o de un yo consciente, centrado y racional; es simplemente diferencia impersonal que va más allá de lo que se significa como humano. Lo que se narra es una experiencia de desubjetivación, de muerte que refleja otras posibilidades de vida, interconectadas e impersonales y que describe Lispector de la siguiente manera:

Ser, es ser más allá de lo humano. Ser hombre no es más que una vicisitud; ser hombre ha sido una compulsión (...) ¿Estoy hablando de la muerte? No, de la vida. No es un estado de felicidad, es un estado de contacto. (...) Lo que llamaba "yo" solo era un añadido de mí. (...) Camino en dirección a la destrucción de lo que he construido, camino a la despersonalización. (...) La despersonalización como la destrucción de lo individual inútil, la perdida de todo lo que se puede perder $\mathrm{y}$, aun así, ser.

(...) Con las manos tranquilamente cruzadas en el regazo, experimentaba un sentimiento de tierna alegría tímida (...) Me estaba aproximando a lo más fuerte que jamás me ocurrió. Me sentía bautizada por el mundo. Tenía en la boca la materia de una cucaracha y por fin había realizado el acto ínfimo que siempre me había faltado. (...) No el acto máximo, como antes había pensado, no el heroísmo y santidad. (...) Me había desheroizado. (...) Por fin mi envoltura se había roto finalmente, y yo era ilimitada. Por no ser, era.

(...) Yo era tan grande ahora que ya no me veía. Tan grande como un paisaje lejano me hallaba lejana, pero perceptible en mis más últimas montañas y en mis más remotos ríos. (2013: 148-154).

Todo este proceso relatado por la protagonista de Lispector, es un trabajo sobre sí mismo, que danza con el azar y traza líneas de fuga. Lo importante es lo que se desencadena y no lo que sucede. El evento intensivo, desheroizante, puede ser comerse una cucaracha, acercarse a las plantas sagradas, separarse de la familia, enfrentar la soledad, ya que es una experiencia que sólo tiene sentido para quien experimenta. El evento intensivo es lo que desencadena y el acontecimiento, según lo presenta De- 
leuze (1989) en "Lógica del sentido", es lo que sucede, aquello en lo que nos transformamos. Es decir, el acontecimiento está en lo que sucede. Es lo que nos espera en lo que sucede, lo que existe en la experiencia que no comprendemos y que nos desgarra desde adentro, des-estratificándonos y llenándonos de una intensidad que no poseíamos. Aunque nos enfrenta a una muerte, también nos señala una vida que pasa a través de la finitud del yo y que configura la creación. Finalmente, querer el acontecimiento no es aceptar simplemente lo que sucede, es buscar intencionalmente la transmutación y asumir una vida que transita en lo incierto y el azar.

\section{Referencias bibliográficas:}

Braidotti, R. (2005) Metamorfosis. Hacia una teoría materialista del devenir. Madrid: Akal. Deleuze, G. Conversaciones. (1999) Valencia: Pre-Textos.

Deleuze, G. (2009) Diferencia y repetición, Buenos Aires: Amarrortu editores.

dos sujeitos está em questão. (1971) Nietzsche y la filosofía. Barcelona: Anagrama.

. (1989) Lógica del sentido. Barcelona: Paidós.

Deleuze, G y Parnet C. (1980) Diálogos. Valencia: Pre-textos.

Deleuze, G. y Guattari, F. (1994) Mil Mesetas. Capitalismo y esquizofrenia. Valencia: Pre-textos.

Lee, M. y Fisher, M. (2009) Deleuze y la brujería. Buenos Aires: Las cuarenta.

Lispector, C. (2013) La pasión según GH. Madrid: Siruela.

Eliade, M. (1998) Lo sagrado y lo profano. Barcelona: Paidós.

Haraway, D. (1999) Las promesas de los monstruos: política regeneradora para otros inapropiados. Política y Sociedad, 30 Madrid, pp 121-163 